\title{
Cadmium Exposure: Health Hazards of Silver Cottage Industry in Developing Countries
}

\author{
PK Sethi MD, a Dinesh Khandelwal MD, a Nitin Sethi MD
}

a Department of Neurology, Sir Ganga Ram Hospital, New Delhi, India

b Department of Neurology, Saint Vincent's Hospital and Medical Center, New York, NY

\section{ABSTRACT}

In countries such as India, the silver jewelry industry is an important cottage industry. Silver is mixed with cadmium and then used to make silver jewelry. During this process there is a formation of cadmium fumes, and the workers inhale the fumes. Cadmium is a neurotoxic and nephrotoxic heavy metal, and there are no national policies to prevent exposure to such chemicals. We will present a case of cadmium induced peripheral neuropathy, nephropathy, and decreased bone density.

\section{BACKGROUND}

Cadmium is a toxic heavy metal, well known for its occupational health risk, $[1,2]$ and cadmium (as a pollutant of air and water) is an increasing public health concern. Inhalation of cadmium fumes or dust is the primary cause of cadmium exposure. Contamination of ground water (wells) and food are the other predominant sources of environmental pollution [1,2]. Cadmium accumulates in the human body a half-life every 15-20 years. Though it is recognized as a neurotoxic and nephrotoxic metal in developed countries, there is not much awareness of its toxicity in developing countries [3]. To the best of our knowledge, this is the first report of cadmium toxicity in the silver cottage industry in India.

\section{CASE SUMMARY}

A 32-year-old male was presented to us. (The man worked as a silver jewelry manufacturer for the past 12 years). The man reported having pain in both ankles when walking and pain over the bilateral lower ribs for the past year-and-a-half. (He was asymptomatic a year-and-a-half ago). The pain was dull and achy, and he relieved the pain by taking rests and avoiding walking. The pain was not associated with any joint swelling, local redness, numbness, tingling sensations, or weakness of limbs. At about the same time as the ankle pain, he also developed pain around the lower ribs. It was described as a dull aching, exacerbated by movements of the trunk and coughing. The pain radiated from back to front in lower thoracic dermatomes. There were no sensory symptoms, and the intensity of pain remained static over time. There was no history of any cranial nerve dysfunction or upper limb symptomatology. His behaviour, memory, ability to concentrate, and other intellectual functions remained unaffected. There was no history of exposure to lead. His family members were not available for clinical evaluations and investigations. Clinically, the patient was found to have bilateral pes cavus with weakness of ankle dorsiflexors, power being grade $3 / 5$ (MRC). Deep tendon reflexes and sensory examination were normal. The spine was normal, and there was no deformity or tenderness over it. A nerve conduction study revealed motor axonal neuropathy involving both common peronial nerves. There were no conduction blocks and no evidence of upper limb involvement. A routine urinalysis revealed significant proteinuria with normal blood urea and serum creatinine. An X-ray of the dorsal spine showed a collapse of the D11 vertebrae with generalized decreased bone density. There was no evidence of interosseous membrane calcification on an X-ray of the forearm. An MRI of the dorso-lumbar spine did not reveal any radicular compression or soft tissue shadow. Since the patient was a silver jewelry worker, a 24-hour urinary cadmium test

Keywords: cadmium, silver cottage industry, peripheral neuropathy, nephropathy 
(by atomic absorption spectrophotometry analysis) was ordered: the result was 20.10 micrograms of cadmium per liter (normal is $<5.00 \mathrm{mcg} / \mathrm{l}$ ). Other investigations (including hemogram, serum chemistry, and blood lead levels) were normal. Chelation was not attempted because it is not useful in the chronically exposed patient. Antioxidants were prescribed and the patient was asked to abstain from work to limit further exposure. He was lost to follow up.

\section{DISCUSSION}

This patient, his brothers, and father participated in the silver jewelry industry for decades. The business is inherited, passed on from father to son and carried out at home. According to the patient, silver was mixed with $30 \%$ cadmium and then used to make silver jewelry. While welding the silver pieces to make jewelry, there was a formation of cadmium fumes that were inhaled by the patient and his family members. The patient, who had chronic exposure to cadmium fumes, was found to have a polyneuropathy.

There are reports of cadmium-induced polyneuropathy, neuropsychiatric manifestations and nephropathy $[4,5,6]$. Pathogenesis of neurotoxicity is unknown. Renal toxicity includes progressive renal insufficiency due to proximal renal tubular dysfunction and glomerular damage. Nephrotoxicity and neurotoxicity has been found to occur independently [6]. The body burden of cadmium, over half of which may reside in kidneys, is usually measured by a urinary estimation of cadmium levels. Both ss2-microglobulin and alpha1-microglobulin serve as organ specific, early effect biomarkers of tubular proteinuria and thus play a role in early detection of nephrotoxicity [7].

Chronic exposure to toxic metals usually goes undetected and unchecked in families from developing countries because people are unaware of the dangers and there are no national policies to prevent and control exposure. (The children in families exposed to cadmium have been found to havediminished intelligence) [8]. There are no statistical data comparing the burden of exposure in developing countries to the burden of exposure in developed countries [9]. Occupational health and safety research prevention in developing countries is mainly focused on large-scale industries. No rules and regulations have been developed for family run cottage industries. Prevention programs, training, education about the hazards of cadmium exposure, suitable precautions, and the development of safer substitutes are critical. True prevention will require the training of local health care providers in the diagnosis and treatment of occupational diseases related to hazards in the cottage industries.

\section{REFERENCES}

1. World Health Organization. World Health Organization international programme on chemical safety (WHO-ICPS). Cadmium. Geneva: WHO, 1992:1-264 (Environmental health criteria 134.)

2. Jarup L, Berglund M, Elinder CG, et al. Health effects of cadmium exposure: a review of literature and risk estimate.

Scand J Work Environ Health 1998; 24(suppl 1): 1-51.

3. McCann M. Hazards in cottage industries in developing countries. Am J Ind Med. 1996 Aug; 30(2): 125-9.

4. Blum LW, Mandel S, Duckett S. Peripheral neuropathy and cadmium toxicity. Pennsylvania Medicine 1989; 92:54-56.

5. Roels HA, Lauwerys RR, Buchet JP, et al. Health significance of cadmium induced renal dysfunction: a 5 years follow up. Br T Ind Med 1989; 46:755-64.

6. Viaene MK, Masschelein R, Leenders J, et al. Neurobehavioral effects of occupational exposure to cadmium: a cross sectional epidemiological study. Occup Environ Med 2000; $57: 19-27$.

7. Wittman R, Hu H. Cadmium exposure and nephropathy in a 28 year old female metals worker. Environ health perspect 2002; 110:1261-6.

8. Thatcher RW, Lester ML, McAlaster R, et al. Effects of low levels of cadmium and lead on cognitive functioning in children. Arch Environ Health 1982; 37:159-66.

9. Gan SL, Tan SH, Pinnagoda J, Tan KT. Cadmium hazard in silver brazing. Ann Acad Med Singapore. 1995 Mar; 24(2): 325-7. 